\title{
Evaluation of Arabidopsis thaliana response to infection by Tomato spotted wilt virus and Groundnut ringspot virus
}

\author{
Elizabete S. Cândido ${ }^{1}$, Lílian S.T. do Carmo ${ }^{1}$, Pollyanna F. Campos ${ }^{1}$, Bárbara Santana ${ }^{1}$, \\ Antônio Carlos de Ávila² \& Betania F. Quirino ${ }^{1}$
}

${ }^{1}$ Genomic Sciences and Biotechnology Program, Universidade Católica de Brasília, CEP 70790-160, Brasília, DF, e-mail: betaniaf@pos.ucb.br; ²Embrapa Hortaliças, CEP 70359-970, Brasília, DF

(Accepted for publication on 31/08/2005)

Corresponding author: Betania F. Quirino

\begin{abstract}
RESUMO
Avaliação da resposta de Arabidopsis thaliana à infecção por Tomato spotted wilt virus e Groundnut ringspot virus Tomato spotted wilt virus (TSWV) é capaz de infetar 20 ecótipos de Arabidopsis thaliana. Também é relatado, pela primeira vez, que A. thaliana é hospedeira de outro tospovírus que ocorre no Brasil, o Groundnut ringspot virus (GRSV).
\end{abstract}

In Brazil the occurrence of different tospovirus species such as Tomato spotted wilt virus (TSWV) and Groundnut ringspot virus (GRSV) has been reported (De Ávila et al., J. Gen. Virol. 74:153. 1993; De Ávila et al., Arch. Virol. 128:211. 1993). Arabidopsis thaliana is currently the most studied plant and has had its genome completely sequenced since the year 2000. The ecotype Columbia of $A$. thaliana has been shown to be a host to TSWV (German et al., Plant Mol. Biol. Rep. 13:110. 1995). Here we expand on this previous report by describing in detail disease symptoms on A. thaliana and evaluating the response of 20 different ecotypes to TSWV. We also describe, for the first time, the symptoms of GRSV infection on Arabidopsis plants.

Arabidopsis thaliana ecotypes CS903, CS920, CS1020, CS1072, CS1084, CS1194, CS1308, CS1354, CS1438, CS1466, CS1492,CS1540, CS1566, CS1594, CS1640, CS1643, CS2223, CS3112, CS6100, CS6699 were obtained from ABRC (Ohio, U.S.A.). Three to four weeks-old plants grown under continuous fluorescent illumination (100 ìmol. $\left.\mathrm{m}^{-2} \cdot \mathrm{s}^{-1}\right), 24{ }^{\circ} \mathrm{C}$ and $50 \%$ relative humidity were used in all experiments. Rosette leaves of all 20 ecotypes were mechanically inoculated with TSWV, isolate BR-01 (De Àvila et al., J. Gen. Virol. 71:2801. 1990). Symptoms of infection appeared two weeks after inoculation and ranged from mild to strong, sometimes leading to plant death, depending on the ecotype. Common symptoms were the development of chlorotic and necrotic spots (Figure 1). Sometimes chlorotic rings and deformation of leaves with curling, as well as purpling of leaves, inhibition of plant growth and reduced fertility were observed. All ecotypes showed positive DAS-ELISA results in at least one of the timepoints tested 12, 20 or 35 days post inoculation (d.p.i.) (Clark \& Adams, J. Gen. Virol. 34:475. 1977). For experiments with GRSV isolate A5, six ecotypes (CS1194, CS1298, CS1308, CS1540, CS1640 and CS6922) were selected and their rosette leaves were mechanically inoculated.
Symptoms such as leaf necrosis and chlorotic and necrotic spots were noticeable two weeks after inoculation. The bolt of many plants became contorted and stunting and inhibition of silique (pod) growth were also observed (Figure 1). Wrinkling of cauline leaves indicates that GRSV infection is systemic on $A$. thaliana. Symptoms correlated with GRSV detection by DASELISA at 14 d.p.i. on all tested ecotypes.

All ecotypes tested were susceptible to the tospoviruses studied. Arabidopsis thaliana is a great model system for performing genetic experiments. Future studies such as mutant screens for increased susceptibility or resistance to TSWV and GRSV will provide the opportunity for uncovering plant genes involved in the plant-tospovirus interaction.

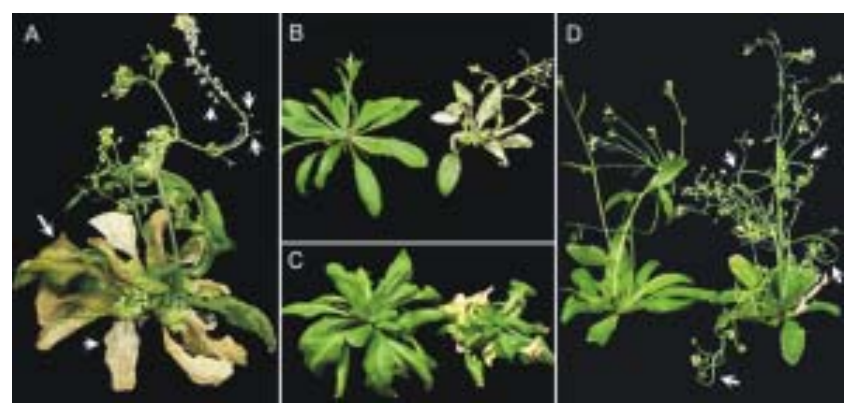

FIG. 1 - Symptoms of Arabidopsis thaliana plants infected with Tomato spotted wilt virus (TSWV) (A and B) and Groundnut ringspot virus (GRSV) (C and D); (A) Ecotype CS1072 displaying leaf necrosis, chlorosis and inhibition of silique development (arrows), 30 days post inoculation (d.p.i.); (B) Ecotype CS3112, 12 d.p.i. Left, mock inoculated control; right, TSWV-infected plant showing inhibition of growth and leaf necrosis; (C) Ecotype CS1540, 15 d.p.i. Left, mock inoculated control; right, GRSVinfected plant showing inhibition of growth, leaf curling, leaf chlorosis and necrosis; (D) Ecotype CS1194, 15 d.p.i. Left, mock inoculated control; right, GRSV-infected plant showing contorted bolts (arrows). 